\title{
CORRESPONDENCE
}

\section{Asbestos, ergot drugs and the pleura}

\section{To the Editor:}

Our recent editorial [1] commenting on the paper by KNOOP et al. [2] and HLLERDAL et al. [3] discussed mainly clinical and aetiological issues regarding the possible interaction between former asbestos exposure and intake of ergot drugs in the pathogenesis of subacute pleural effusions or thickening. As the ultimate outcome of pleural effusions or thickening following treatments with bromocriptine in former asbestos workers becomes more clear, issues related to charges against prior occupational exposure and attending compensation will need to be considered in more depth. In this setting, the acute pleural disease and the permanent changes in lung function are distinct problems, which may all justify some form of compensation.

As we feel from the papers cited above [2, 3], and from our ongoing personal experience with further cases (unpublished), bromocriptine-induced loss of lung function is quite aggressive and, more often than not, recovers only partially after the drug has been stopped. The resulting permanent impairment in lung function is likely to bring such patients to Boards of Compensation for Occupational Lung Diseases, and a common attitude is desirable.

In any former asbestos worker sent to Board of Compensation, we suggest that a systematic inquiry regarding current or past exposure to bromocriptine (or other ergots) should be performed, especially when the pleural thickening or effusion is progressing rapidly, an unusual finding in asbestos-related disease. Also, a systematic search for previous chest radiography is necessary, in order to evaluate the time-course of ongoing pleural changes properly. In the patient exposed to an ergot drug, withdrawal of the drug should be suggested. However, care should be taken in Parkinson's disease, as the neurological status may deteriorate following the interruption of treatment with bromocriptine [2].

During the acute phase of pleural disease induced by asbestos and/or bromocriptine, all necessary investigations (laboratory work-up, chest radiographs, computed tomography scans and casual pleural biopsy, thoracoscopy, thoracotomy or any other relevant test or procedure) should be conducted without delay. In principle, these costs of care should ultimately be covered by Funds for Occupational Lung Disease, even though the drug may eventually be considered causative.

After drug withdrawal, the clinical status and pulmonary function tests should be followed (e.g. every 1-2 months for 6-12 months, depending on the severity) and evaluated at 6-12 months in view of compensation for any residual, irreversible loss of lung function. Our patients are currently followed up in this way. While we believe that the patient's lung function should have stabilized or recovered by $6-12$ months if the drug was causative, this remains to be documented. At $6-12$ months, any residual restrictive lung function defect should be ascribed to asbestos and compensated as such, even though the drug may be the cause of the deterioration. This is in keeping with the medicolegal principles of benefit of the doubt and globalization of impairment. In patients with complete recovery towards baseline at 6-12 months, there would be little or no change in compensation compared with the period prior to the pleural disease.

We should be happy if the Scientific Group for Occupational and Environmental Health from the European Respiratory Society would review these problems and preliminary proposals, and issue recommendations to handle these clinical situations with the best level of justice and harmony within the European Community. In the meantime, and in keeping with earlier suggestions about drugs [4], we have opened up a registry of asbestos and bromocriptine cases, which welcomes any new case with strict confidentiality. This registry may send to any applicant (available by writing to any of the authors) a questionnaire with suggestions for collecting clinical and radiographic data, and planning follow-up. Thereby, the European Respiratory Society will fulfil one of its missions, namely to identify and gather novel information regarding lung diseases.

\section{Ph. Camus, G. Hillerdal, P. De Vuyst}

Centre Hospitalier Universitaire, B.P. 1542, F-21034 Dijon, France. Fax: 33380293251.

\section{References}

1. De Vuyst P, Pfitzenmeyer P, Camus P. Asbestos, ergot drugs and the pleura. Eur Respir J 1997; 10: 2695-2698.

2. Knoop E, Mairesse M, Lenclud C, Gevenois P A, De Vuyst $P$. Pleural effusion during bromocriptine exposure in two patients with preexisting asbestos pleural plaques: a relationship? Eur Respir J 1998; 10: 2898-2901.

3. Hillerdal G, Lee J, Blomkvist A, et al. Pleural disease during treatment with bromocriptine in patients previously exposed to asbestos. Eur Respir J 1997; 10: 2711 2715.

4. Camus P. Respiratory disease induced by drugs. Eur Respir J 1997; 10: 260-264. 